\title{
Renan Monteiro - Fragmentos sobre o medo
} Rio de Janeiro: Multifoco, 2016

\author{
Rodrigo Fonte
}

Em sua primeira e única entrevista, concedida a um programa de TV, Clarice Lispector afirmou que o papel do escritor na contemporaneidade é "falar o menos possível". Terminava, naquela ocasião, a década de 1970, e de lá para cá a literatura brasileira foi ficando, de fato, mais enxuta, confirmando a percepção da escritora. "Falar o menos possível" é, antes de tudo, abrir espaço para as elucubrações do leitor, ou, ainda, para a função que, segundo Wolfgang Iser (2013), lhe cabe: o de suplementar as narrativa s com os elementos de sua imaginação, conforme a delimitação de sua realidade.

Assim, jovens autores do século XXI se lançam no meio literário aderindo a uma tendência estética que valoriza o texto fragmentado - que tem sido, aliás, resultado de um estilo de vida pós-pós-moderno, cuja essência está na liquidez das ações e dos sentimentos, na necessidade de se hiperconectar e, ao mesmo tempo, de se desligar do mundo circundante.

Vivemos um tempo de paradoxos, de emoções experienciadas no limite do possível, em que ninguém mais procura constituir uma individualidade: já é parte de uma grande massa digitalizada que escapole, por isso mesmo, das responsabilidades pela existência.

O retrato desenhado aqui aponta para um momento crítico de pessimismo e terror generalizado, contra o qual já vem se movimentando a atual e necessária circunstância política e social de reinvindicação e de apropriação definitiva dos direitos humanos. O presente, ao que tudo faz provar, se constitui pelo ataque continuado a esses direitos, vestígio retrospectivo de uma ordem de exclusão e extermínio dos que assumem sua diferença, bem como pela veloz mobilidade das técnicas e tecnologias, das imagens e suas mensagens, dos povos e suas ideologias. A imaginação artística, assim, enquanto um organismo positivamente contaminado pelos efeitos sociais, responde a tais fluxos, a essa abominável e inadmissível construção de barreiras sociais e culturais cada vez mais sólidas que fronteiram, sobretudo, o conhecimento.

No entender do antropólogo Arjun Appadurai (2001), a imaginação deixou de ser uma extensão da inteligência individual, válvula de escape do cotidiano atribulado e alienante, ou simplesmente uma realização estética. Ela é, ao contrário, o que em verdade tira a venda dos olhos do homem comum, conduzindo-o a uma ação de resistência à violência e de reestruturação de sua existência. Eis a utilidade da arte - o que, em termos de imaginação de uma vida social, significa a composição do propósito da chamada globalização.

Atento a semelhantes questões, Renan Monteiro estreia na literatura brasileira explorando uma vertente atualíssima, não só em termos estruturais - em se tratando de um livro de fragmentos - mas também quanto ao seu repertório temático: o medo. Paralelo a isso, o autor põe em cena encontros fugazes, silenciosos e, talvez por isso, repletos de quimeras. A rápida satisfação amorosa e sexual, a qual se segue o descarte, serve de pretexto para que as vozes narrantes de cada miniconto possam expor as motivações possíveis do medo. "Nesse curto instante, somos apenas estranhos, estranhos tão familiares e íntimos, conectados; porém repudiados pela invisibilidade que somente um olhar rico em arbítrio pode oferecer" (Monteiro, 2016, p. 7), explica o narrador de "O olhar". O piscar dos olhos aqui funciona como uma metáfora da brevidade e da artificialidade com as quais vamos nos habituando. $\mathrm{O}$ eu torna $\mathrm{o}$ outro um objeto de desejo e repulsa; lança sobre ele suas expectativas e o consequente temor de que todas sejam sumariamente frustradas. Envolver-se e apartar-se de maneira circular fundamenta, pois, o que de fato subjaz no desvio do inconsciente. Trata-se de uma solução dúbia, principalmente adotada por sujeitos cujo prazer mórbido se dá através de uma intensa

\footnotetext{
* Doutorando em letras vernáculas (literatura brasileira) na Universidade Federal do Rio de Janeiro (UFRJ), Rio de Janeiro, RJ, Brasil. (Dorcid.org/0000-0003-0961-4028. E-mail: r.jill@ hotmail.com
} 
minimização do outro, a seu ver sempre vulnerável por desejar ser amado de maneira incondicional sem qualquer zelo à sua integridade física e emocional.

Um tipo como esse aparece no fragmento "Alguém está andando", em que "estar" é o mesmo que seguir na contramão, ir no contra fluxo e causar, deliberadamente, a cisão do outro. É se apropriar do que não é próprio no entrecruzar de caminhos, motivando o desdobramento de um ponto bastante humano quase nunca percebido. Eis a individualização exacerbada, ou ainda a solidão buscada a fim de camuflar o medo de investir no amor. Pois, conforme prevê Zygmunt Bauman:

[...] esse mundo, como os reality shows têm mostrado vividamente e provado de forma convincente, se refere "a quem manda quem para a lata do lixo"; ou melhor, quem o fará primeiro, enquanto ainda há tempo de fazer com os outros o que eles muito desejariam, se tivessem a chance, fazer com você - e antes que eles consigam agir de acordo com os seus desejos (Bauman, 2008, p. 39).

Não é possível ser um elemento diferente senão "eu" - parecem afirmar alguns dos narradores encontrados nos fragmentos. Sugerem, pela semelhança de juízos, serem um e o mesmo, desdobrados e mascarados aqui e ali; outros se apresentam com uma dicção diferente, representando crenças íntimas e sociais de sujeitos que não cansam de ficar à espera do amor, que escamoteiam seus erros recorrentes e que não fazem qualquer manobra para se desvencilhar da viciosa ciranda de ser escolhido e ser buscado, "o interior gritando: 'as mágoas de criança'" (Monteiro, 2016, p. 57).

Está claro, portanto, que nessa experiência literária Renan Monteiro faz uso de recursos imagéticos bem refinados (embora vez ou outra algo ingênuo nos valores descritos) para questionar uma geração infantiloide, que finge o tempo todo estar bem, receosa da melancolia exposta; um grupo de jovens e adultos que não se sente capaz de sustentar as contrariedades da vida, os sofrimentos - e que tampouco consegue perceber com clareza a poeticidade dos fatos do dia a dia mais banal.

Era como se a vida tivesse se automatizado em meio às milhares de pequenas rotinas, que aos poucos foram conquistando mais e mais espaço, tomando parte de sua vida e finalmente se tornando sua própria existência: acordar, se banhar, trabalhar, comer, transar, sem refletir. Agora se perguntava: o que a vida se tornou? Será que ignorei a sorte? Agora estou velho, velho e sozinho. Assim morrerei, esse dia está próximo... próximo... estou muito velho... muito velh... (Monteiro, 2016, p. 31).

O medo da passagem do tempo, da velhice iminente, quando falha a consciência de que se viveu a juventude da maneira que se pôde, é de partida uma recorrência clichê que em certa medida o autor abusa em determinados fragmentos. No entanto, isso que em termos críticos poderia sugerir uma inaptidão estética, sob a perspectiva da motivação da obra, visivelmente gerada a partir de uma tendência midiática e digital, torna evidente a tentativa de dar mostras de certo segmento cultural, conforme frases como "só há amor quando existe entrega", típicas em melodramas televisivos e cinematográficos.

Também a influência dos meios audiovisuais deve ser contemplada como uma marca interessante da nova configuração literária - não apenas brasileira, mas mundial.

O escritor e professor universitário Godofredo de Oliveira Neto, em posfácio a um livro organizado por ele acerca da literatura pós-pós-moderna, faz um panorama das tendências encontradas nas obras surgidas desde a década de 1990:

A cena literária, sobretudo a partir da década de 90, passa a se caracterizar por uma massificação de escritores, pela democratização criativa usada e abusada por todos, pela consolidação do individualismo, pelo umbiguismo autobiográfico e pelo descaso, às vezes absoluto, com a tradição - "não preciso ler poetas do passado para ser poeta", ouvia-se pelos corredores das universidades. A classe média, a urbe e os fragmentos comunitários da cidade devoradora são escolhidos como temas e as ansiedades individuais trazidas à frente da cena. O roteiro cinematográfico sai fortalecido. É claro que a narrativa virá vazada em linguagem crua e direta. A violência e a competição desenfreada são moedas 
correntes. Mas houve uma abertura sadia para mais segmentos sociais e para novos experimentos de linguagem e de estilo (Oliveira Neto, 2011, p. 224).

A abertura referida por Oliveira Neto já é por si só uma relevante quebra de paradigmas no campo literário; um avanço em termos de objeto narrativo, tanto quanto de oportunidade de novos autores se lançarem no mercado, conquistando um espaço antes apenas ocupado pelo cânone no que concerne ao interesse do leitor crítico e do comum.

Com Fragmentos sobre o medo, Renan Monteiro torna manifesto ficcionalmente, ao dizer que "o grito era o silêncio; a dor, o tédio" (2016, p. 75), um estado de es pírito afetado por graves doenças emocionais e psicológicas, causadoras dos maiores rompimentos, das rasuras mais espúrias. Apesar disso, a potência literária com que constrói suas pequenas histórias não transmite ao leitor qualquer sensação de que sai de um poço sem fundo de sentimentos opacos e desoladores. Há, sim, um texto vivaz, espirituoso, muitas vezes irônico, que tira de nós a ilusão de que visitamos vidas comuns de tipos humanos em um momento específico, brevíssimo, de seu tempo; um texto, em suma, dialogicamente ajustado à proposta de Antonio Candido (2014, p. 21), para quem "a literatura, como fenômeno de civilização, depende, para se constituir e caracterizar, do entrelaçamento de vários fatores sociais". Nesse aspecto, os fragmentos urdidos por Renan Monteiro valem como um desnudamento - movido, sim, por uma substância dramática forte e costumeira nos diversos veículos artísticos, porém com o fascinante propósito de recompor o mais-quehumano na esfera extraliterária, tirando abruptamente o leitor da impassibilidade.

\section{Referências}

APPADURAI, Arjun (2001). Grassroots Globalization and the Research Imagination. In: APPADURAI, Arjun (Ed.). Globalization. Durham, N.C., London: Duke University Press. p. 1-21.

BAUMAN, Zygmunt (2008). Medo líquido. Tradução de Carlos Alberto Medeiros. Rio de Janeiro: Zahar.

CANDIDO, Antonio (2014). Crítica e sociologia (tentativa de esclarecimento). In: CANDIDO, Antonio. Literatura e sociedade. Ouro sobre Azul. p. 13-25.

ISER, Wolfgang (2013). O fictício e o imaginário: perspectivas de uma antropologia literária. Tradução de Luiz Costa Lima. Rio de Janeiro: EdUERJ.

OLIVEIRA NETO, Godofredo (2011). Posfácio. In: OLIVEIRA NETO, Godofredo (Org.). O pós-pós moderno: novos caminhos da prosa brasileira. Rio de Janeiro: Multifoco. p. 223-226.

MONTEIRO, Renan (2016). Fragmentos sobre o medo. Rio de Janeiro: Multifoco. 